\title{
Effect of Slag Composition on Iron Nuggets Formation from Carbon Composite Pellets
}

\author{
Alberto Eloy Anduze Nogueira, Marcelo Breda Mourão*, \\ Cyro Takano, Dener Martins dos Santos \\ Department of Metallurgical and Materials Engineering, \\ Polytechnic School, University of São Paulo, \\ Av. Prof. Mello Moraes, 2463, CEP 05508-900 São Paulo, SP, Brazil
}

Received: November 13, 2009; Revised: March 12, 2010

\begin{abstract}
Iron-carbon nuggets can be obtained by high temperature reduction of iron ore by carbonaceous material when both are agglomerated together as a carbon composite pellet. During this process, the stable oxides contained in the materials will form a slag. This work investigates the effect of this slag composition on iron nugget formation. Pellets were prepared with iron ore and two different carbonaceous materials. Through the addition of Portland ${ }^{\circledR}$ cement, silica and alumina the slag composition was varied to adjust the expected liquidus temperature to 1573 and $2273 \mathrm{~K}$. It has been shown that the formation of iron nuggets is favored for slags presenting low liquidus temperature. In order to further investigate this phenomenon, pellets containing iron powder and carbonaceous material, together with previously prepared slags, were also submitted to high temperature, and it has been shown that iron carburization depends on slag composition.
\end{abstract}

Keywords: iron nuggets, composite pellets, carbothermic reduction

\section{Introduction}

The iron ore reduction processes can be classified into two groups according to the kind of reducer: on natural gas basis or carbon one. The process based on carbon is largely used because the blast furnace has a high development degree. The process based on natural gas represents $7 \%$ of iron annual world production distributed as follows: $67 \%$ from Midrex technology, 22\% on HYL technology and $11 \%$ related to other technologies. The fact that they were based on natural gas implies that they must be localized at an accessible place in order to get cheaper natural gas which determines the economic feasibility. Because of it, many iron making companies are developing new processes based on carbon. Self-reducing processes are emerging ones in this direction ${ }^{1}$.

In self-reducing processes the reducer is in the agglomerate composition, the reactor is more compact and it is not necessary to use special fuels, like the expensive metallurgical coke. This and other facts, motivated the development of new ironmaking technologies based on self-reduction (like Tecnored ${ }^{\circledR}$, Fastmet, Inmetco, Dryiron, Redsmelt, ITmk $3^{\circledR}$, etc.), in order to produce metallic iron as an alternative to the traditional techniques ${ }^{2}$. The main problem is that the self-reducing agglomerates with inorganic binders loose mechanical strength at the temperature range of 1100 to $1450 \mathrm{~K}$. At temperatures higher than $1450 \mathrm{~K}$ the reduced iron starts to sinter and increases again this strength.

The ITmk $3{ }^{\circledR}$ process has been developed by Kobe Steel to produce iron nugget. On this process, only 2 or 3 layers of self-reducing pellets are charged in rotary hearth furnace and quickly heated above $1450 \mathrm{~K}$. Maximum temperatures above $1623 \mathrm{~K}$ allow the formation of liquid iron and slag. Under appropriate processing conditions, metal and slag are easily separated ${ }^{3}$.
The iron carbon nugget product is obtained in a few minutes with carbon content between $3-5 \%$. The FeO content of the slag is low. As the material does not present pyrophoric behavior, transportation and stock are facilitated. The ITmk $3^{\circledR}$ product can be used to charge the electric arc furnace (EAF) or basic oxygen furnace (BOF), as scrap substitute, with increasing productivity and efficient energy use ${ }^{4}$.

The present work aims to find a better understanding of ironcarbon nuggets formation from iron oxides-carbon composite pellets, and the interrelation between slag melting and iron carburization.

Iron ore carbothermic reduction can be performed with kinetic advantage if iron ore and carbonaceous material are agglomerated together as a carbon composite pellet which will be heated in suitable equipment in order to set the necessary heat to the endothermic reaction. When composite pellets are heated at high temperature, the metallic iron formed after the reduction of iron oxides can melt, partially or totally, depending on the temperature and the degree of carburization of the product. The oxides in the ore, in the ashes of the carbonaceous material and in the binder, if applied, may react to form a slag. It has been pointed out that if the process is performed at a temperature higher than the liquidus temperature of both, ironcarbon and slag, an iron nugget separated from the slag will be the final product ${ }^{5}$.

Matsumara et al. ${ }^{6}$ presented results of iron carbon nuggets formation after high temperature $(1773 \mathrm{~K}$ ) reduction of magnetite by metallurgical coke; the authors reported that the carbon content in the iron reached $1.7 \%$. Meissner et al. ${ }^{3}$ developed a reduction and melting model of carbon composite iron ore pellets; their model predicts, for a $17 \mathrm{~mm}$ diameter pellet composed of $76 \%$ magnetite ore, $22 \%$ medium volatile coal and bentonite (balance), that liquid iron-carbon will appear after around 8 minutes at $1723 \mathrm{~K}$, after 12 minutes at $1648 \mathrm{~K}$

*e-mail: mbmourao@usp.br 
and that there will not form liquid iron at $1573 \mathrm{~K}$ at least in the first 16 minutes. These authors assumed that carburizing of iron would occurs through the gas phase; the model does not take in account the influence of the slag in the melting process. Matsui et al. ${ }^{7}$ pointed out that if the iron ore gangue covers the reduced iron, it has first to partially melt to permit the contact between iron and graphite, followed by carburizing and melting of iron-carbon alloy.

The temperature needed to obtain the nugget depends on the carbon content of the iron and on the composition of the slag that are the determining factors on their liquidus temperature.

A comprehensive work on the slag effect at the process of iron carburization was carried out by Ohno et al. ${ }^{8}$, performing experiments aiming to simulate the conditions of the cohesive zone of blast furnace. They proposed that when the oxide of iron contained in the slag enters in contact with solid carbon, it is immediately reduced and a particle of iron and a bubble of $\mathrm{CO}$ are formed. The iron particle is carburized by solid carbon and melts at the slag-carbon interface. The liquid iron-carbon particle is carried from the slagcarbon interface to the slag-iron interface due to the slag flow based on the difference of surface tension (Marangoni effect). The liquid iron-carbon particle coalesces immediately at the solid iron surface and the carbon is spread out. The reduced iron will be carburized continuously according to this sequence.

\section{Experimental}

The iron ore used in the experiments was Vale Carajas pellet feed containing $67.6 \%$ Fet, $0.67 \% \mathrm{SiO}_{2}, 0.61 \% \mathrm{Al}_{2} \mathrm{O}_{3}$, and particle size $91 \%$ smaller than $45 \times 10^{-6} \mathrm{~m}$. The carbonaceous materials were graphite containing $99.3 \%$ carbon and devolatized wood charcoal containing $88.6 \%$ fixed carbon and $11.4 \%$ ashes. PA grade iron powder (below $100 \#)$ was also used in some experiments. Portland ${ }^{\circledR}$ cement, silica and alumina were used as binder and/or slag forming constituents, and Table 1 presents the chemical composition of the Portland ${ }^{\circledR}$ cement used in this work, which is one of high initial strength.

For the carburizing experiments, pellets were made containing 95 wt. (\%) PA grade metallic iron mixed with 5 wt. (\%) graphite, and wax was used as a binder. Before the experiment, the wax was eliminated by heating at $723 \mathrm{~K}$. Portland ${ }^{\circledR}$ cement, silica and alumina were used to add slag forming components to some pellets, in different proportions to form high or low liquidus temperature slags, as shown at Table 2. Pellets with these additions contained $11.4 \mathrm{wt}$. (\%) slagforming substances. This value was chosen because it corresponds to the amount of slag forming substances that would exist in pellets

Table 1. Chemical analysis of the Portland ${ }^{\circledR}$ cement used at the experiments.

\begin{tabular}{cclc}
\hline Substance & Wt. $(\%)$ & Substance & Wt. (\%) \\
\hline $\mathrm{CaO}$ & 64.3 & $\mathrm{~K}_{2} \mathrm{O}$ & 0.73 \\
$\mathrm{SiO}_{2}$ & 19.05 & $\mathrm{MgO}$ & 0.55 \\
$\mathrm{Al}_{2} \mathrm{O}_{3}$ & 4.92 & $\mathrm{Na}_{2} \mathrm{O}$ & 0.04 \\
$\mathrm{Fe}_{2} \mathrm{O}_{3}$ & 2.78 & Free CaO & 1.01 \\
$\mathrm{SO}_{2}$ & 2.63 & others & 3.99 \\
\hline
\end{tabular}

Table 2. Calculated composition of the high and low liquidus temperature slags, weight $\%$.

\begin{tabular}{cccc}
\hline & $\mathrm{CaO}$ & $\mathrm{SiO}_{2}$ & $\mathrm{Al}_{2} \mathrm{O}_{3}$ \\
\hline $\begin{array}{c}\text { High liquidus temperature slag } \\
\text { (T. liquidus } \approx 2273 \mathrm{~K} \text { ) }\end{array}$ & 72.85 & 21.58 & 5.57 \\
$\begin{array}{c}\text { Low liquidus temperature slag } \\
\text { (T. liquidus } \approx 1573 \mathrm{~K} \text { ) }\end{array}$ & 23.33 & 62.86 & 13.81 \\
\hline
\end{tabular}

of iron ore and graphite with 7 wt. (\%) addition of Portland ${ }^{\circledR}$ cement, after reduction, which were used in subsequent experiments. The carburization experiments were performed at $1673 \mathrm{~K}$ during 600 seconds under argon flow, in a tubular furnace.

For the reduction-melting experiments, composite pellets were prepared in order to keep the $\mathrm{Fe}_{2} \mathrm{O}_{3}$ : $\mathrm{C}$ ratio equals to $1: 3$ (carbon necessary for the reduction reactions) plus the amount of carbon corresponding to $5 \%$ of the iron, for carburizing the metal. The iron ore-graphite mixture was composed of $79.9 \%$ iron ore and $20.1 \%$ graphite. Addition of Portland ${ }^{\circledR}$ cement as a binder introduces some substances that will not be reduced by carbon, and will form a slag during the process. The main components of this slag will be the oxides of calcium, silicon and aluminum, as shown at Table 1. Assuming that the iron oxides in the cement will be reduced, and also adding to the amount of $\mathrm{CaO}, \mathrm{SiO}_{2}$ and $\mathrm{Al}_{2} \mathrm{O}_{3}$ the other basic, acid and amphoteric oxides, respectively, the composition of the slag formed when mixtures iron ore-graphite-Portland ${ }^{\circledR}$ cement are reduced and melted can be calculated, and the result is shown on Table 2. The liquidus projection diagram of $\mathrm{CaO}-\mathrm{SiO}_{2}-\mathrm{Al}_{2} \mathrm{O}_{3}$ system is presented in Figure 1. It is possible to estimate the liquidus temperature of the expected slag as $2273 \mathrm{~K}$, much higher than the process temperature. By adding $\mathrm{SiO}_{2}$ and $\mathrm{Al}_{2} \mathrm{O}_{3}$ to this slag, it is possible to change its composition in order to get a slag with a lower liquidus temperature, as shown at Table 2 and Figure $1^{9}$. Two types of pellets were made: one with the addition of 7 wt. (\%) Portland ${ }^{\circledR}$ cement to the mixture iron ore-graphite, thus producing a high liquidus temperature during the reduction-melting process, and the other with the addition of $7 \%$ of a mixture of Portland ${ }^{\circledR}$ cement, silica and alumina, thus producing the same amount of slag as the previous one, but with a low (1573 K) liquidus temperature slag. In both cases, after reduction the total amount of slag is expected to be the same, $11.4 \mathrm{wt}$. (\%).

The first set of experiments were performed isothermally at 1573 or $1673 \mathrm{~K}$, followed by experiments in which the pellets were first heated to $1573 \mathrm{~K}$ and then the temperature was raised to $1673 \mathrm{~K}$. The experiments were carried out in a thermogravimetric system with $\mathrm{SiC}$ resistance tubular furnace, under an argon flow of $2.0 \mathrm{~L} / \mathrm{min}$, one pellet at each run. The sample was suspended by $\mathrm{Ni}-\mathrm{Cr}$ wire attached to an electronic balance and the pellet weight could be recorded during the run; the weight loss was used to calculate the reaction fraction in some experiments.

Similar experiments were also performed employing charcoal in the composite pellets, without and with the addition of small amounts of silica and alumina in order to decrease the liquidus temperature of the prospective slag.

\section{Results and Discussion}

\subsection{Reduction experiments}

Figure 2 presents the results of reaction fraction as a function of reaction time for iron ore-graphite pellets, without binder, at 1573,1623 and $1673 \mathrm{~K}$. One can see that the reaction is very fast at these temperatures, and that an increase in temperature significantly increases the reaction rate. The experiment performed at $1673 \mathrm{~K}$ presented an apparently wrong result, i.e., a reaction fraction higher than 1 ; this result was due to the fact that the weight loss was caused not only by the release of the $\mathrm{CO}$ and $\mathrm{CO}_{2}$, but also by projection of materials out of the pellet. At this temperature, the reaction is so fast that occurs dragging of powdery materials from the pellets by the flow of gaseous products, as illustrated in Figure 3. This phenomenon also occurred at $1623 \mathrm{~K}$, but with lower intensity than at $1673 \mathrm{~K}$. In any of these experiments occurred the formation of iron nuggets separated from the slag. It is postulate that at $1573 \mathrm{~K}$ 


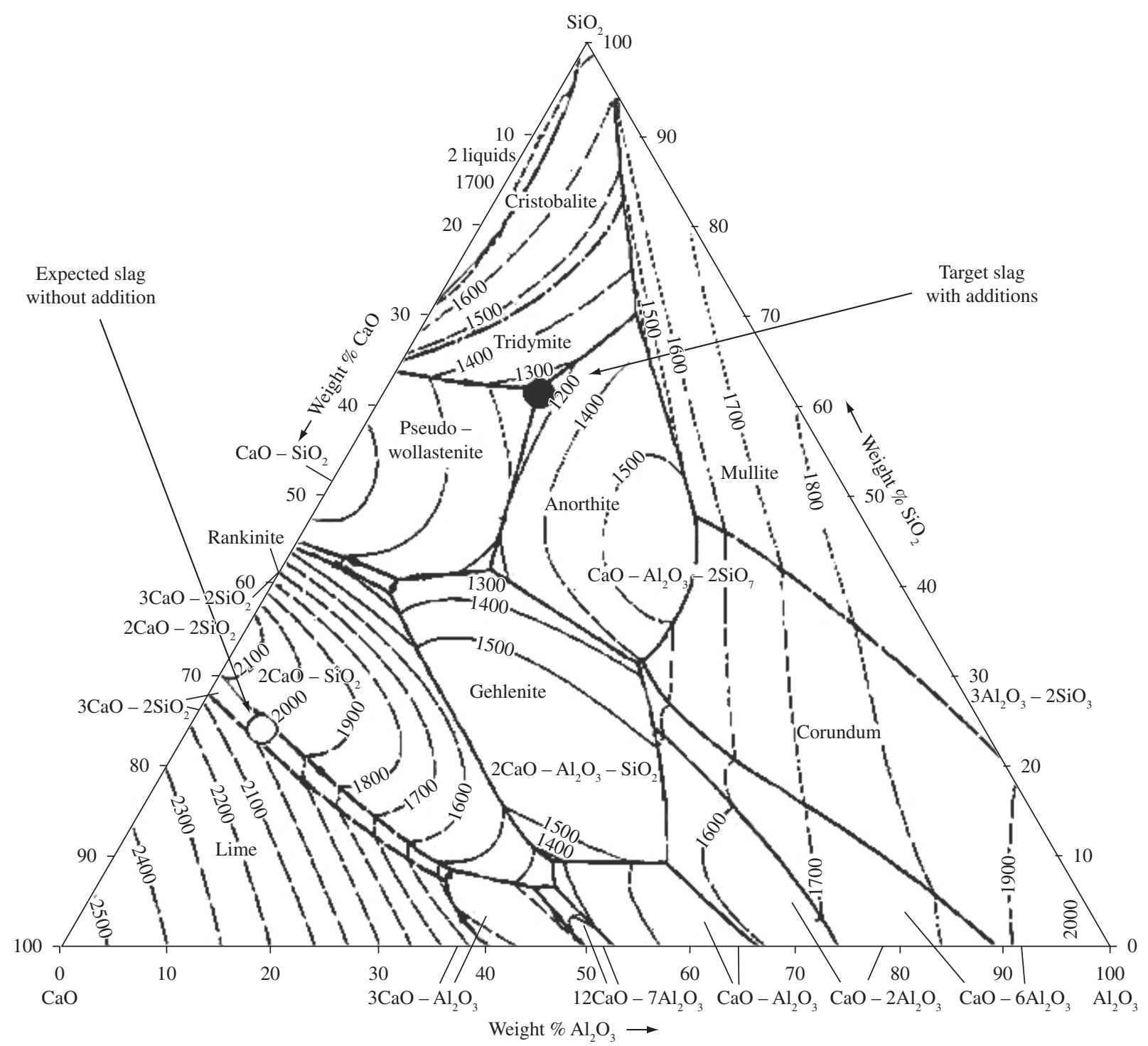

Figure 1. Liquidus temperatures of the $\mathrm{CaO}-\mathrm{SiO} 2-\mathrm{A} 12 \mathrm{O} 3$ system and the expected slags without and with additions?

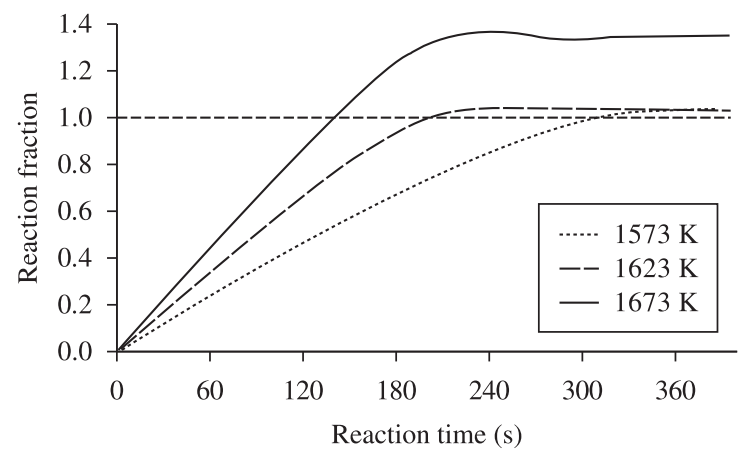

Figure 2. Reaction fraction as a function of time for iron ore-graphite composite pellets heated at different temperatures.

the carbon content of the iron was not enough to attain the liquidus temperature of the iron-carbon alloy due to a low carburizing rate, whereas at $1673 \mathrm{~K}$ the same occurred due to loss of carbon caused by the violent flow of product gases. At the intermediate temperature of $1623 \mathrm{~K}$, both the carburizing rate and the carbon loss could have prevented the nugget formation.

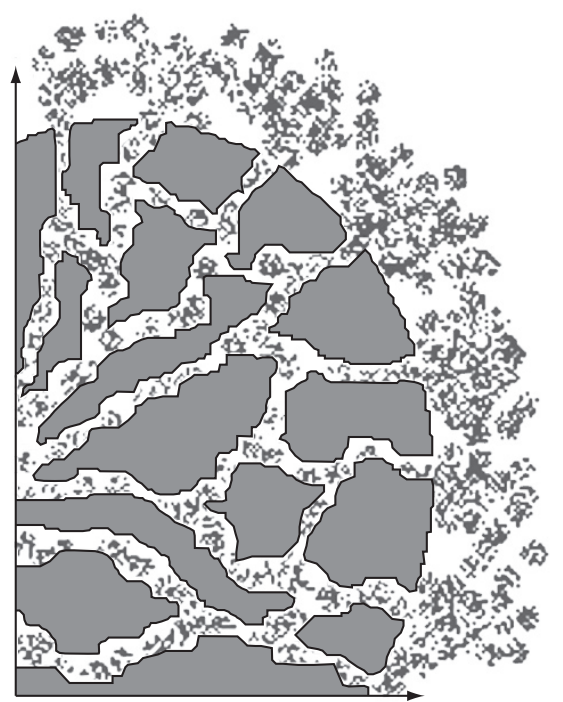

Figure 3. Schematic illustration of particulate materials loss due to the flow of gaseous product from the pellet at high temperatures. 
In an industrial process aimed at producing iron nuggets from iron ore-carbon composite pellets, the process will not be performed isothermally; rather it will submit the pellets to a certain heating rate, and the reduction and melting process will occur under the furnace thermal cycle. In order to verify if the reduction and melting process would overlap, reduction experiments under two different thermal cycles were performed.

Composite pellets were heated at different heating rates ( 50 and $100 \mathrm{~K} / \mathrm{min}$ ) in a tubular furnace under argon flow and the reaction fraction was measured by interrupting the experiment at several time intervals, one pellet used for each measurement. Weight loss was used for the determination of the reaction fraction. Figure 4 presents the reaction fraction as a function of reaction time for both heating rates. One can see that for the heating rate at $100 \mathrm{~K} / \mathrm{min}$, when the pellet reaches $1573 \mathrm{~K}$ around $40 \%$ of reaction was complete, and above $95 \%$ reaction was complete when it reaches $1673 \mathrm{~K}$, whereas for the heating rate of $50 \mathrm{~K} / \mathrm{min}$ above $90 \%$ of the reaction was complete when the pellet reaches $1573 \mathrm{~K}$. These results imply that the reduction step and the subsequent melting step practically do not overlap, because the reduction is almost complete when the system reaches the temperatures in which iron carburization and slag formation and melting (in the case of low liquidus temperature slag) can occur at significant rate. Besides, the phenomenon of carbon loss does not occur. Based on these results, further experimental work was performed in two steps, first heating the pellets to $1573 \mathrm{~K}$ to promote the carbothermic reduction without carbon loss, and then heating to $1673 \mathrm{~K}$ to study the nuggets formation.

\subsection{Carburizing experiments}

Figure 5 shows the pellets with metallic iron and graphite, after the experiment, and Table 3 presents iron carbon content in each experiment, analyzed by the combustion method.

One can see that the slag retards the iron carburization by graphite relative to the slag-free system, and that the low liquidus temperature slag is less harmful than the high liquidus temperature slag. In the latter case, as shown at Figure 1, the iron obtained occurs as several small nuggets, whereas with the low liquidus temperature slag occurs the formation of a single and bigger nugget. In this way, it becomes clear that the slag composition effect is related not only to their own melting, but also affects the carburization and consequently the melting of the iron-carbon alloy obtained.

\subsection{Reduction-melting experiments}

This experimental series pellets containing iron ore, graphite and slag forming components were used, for high and low liquidus temperature slags. In the former case, the pellet with $7 \%$ Portland $^{\circledR}$ cement, and in the later $7 \%$ with a mixture of Portland ${ }^{\circledR}$ cement, silica and alumina. Table 2 shows the expected composition of the slags. The pellets were first heated to $1573 \mathrm{~K}$ for 600 seconds in order to promote the reduction of iron ore without melting the products. Immediately after the reduction the pellets were heated to $1673 \mathrm{~K}$ and maintained at this temperature for 600 seconds. Figure 6 presents pictures of the pellets after the experiment.

One can see that the pellet with $7 \%$ of Portland ${ }^{\circledR}$ cement maintains its shape after reduction at $1573 \mathrm{~K}$ followed by heating to $1673 \mathrm{~K}$, presenting no separation of an iron nugget from the slag. On the other hand, the pellet with $7 \%$ of a mixture of Portland ${ }^{\circledR}$ cement, silica and alumina, that will form a slag with an expected liquidus temperature of $1573 \mathrm{~K}$ (against $2273 \mathrm{~K}$ expected for the slag formed only from Portland ${ }^{\circledR}$ cement addition), presented an iron nugget separated from the slag after the experiment.

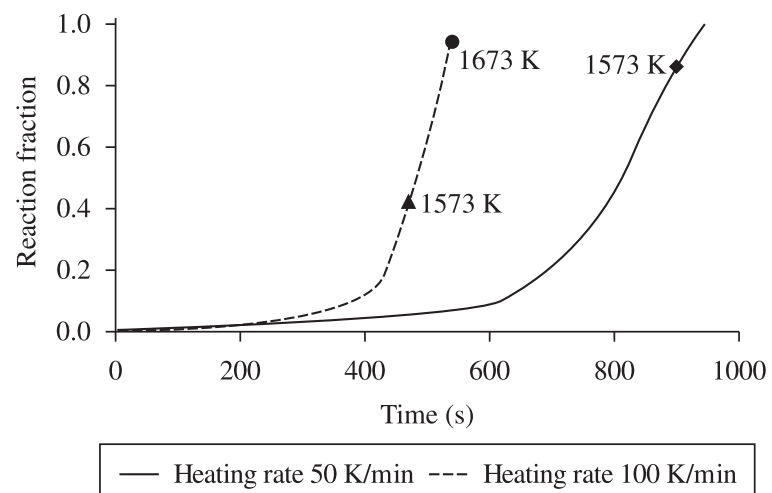

Figure 4. Reaction fraction as a function of time for non-isothermal reduction of iron ore by graphite; the starting time was taken when the temperature was $773 \mathrm{~K}$.
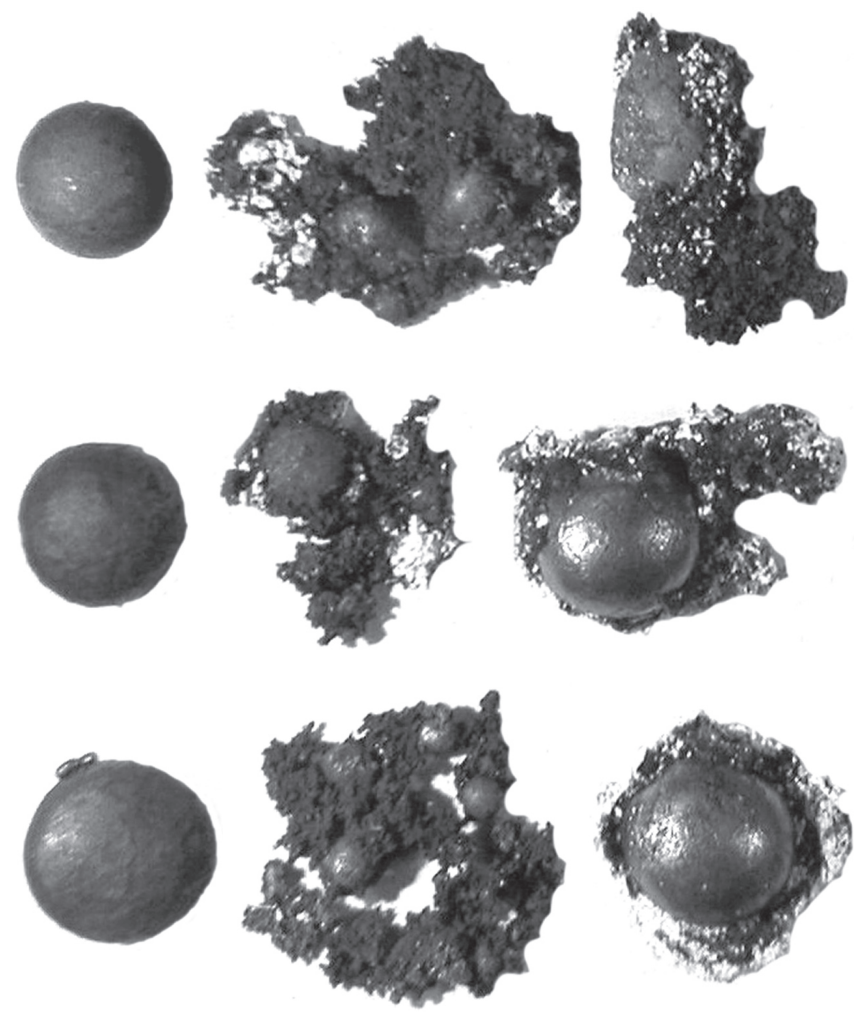

Figure 5. Left: iron-carbon nuggets without ashes formed from pellets with metallic iron and graphite; center: several small iron-carbon nuggets formed from pellets with metallic iron, graphite and high liquidus temperature slag; right: iron-carbon nuggets separated from the low liquidus temperature slag.

Table 3. Iron carbon content after the carburizing experiments.

\begin{tabular}{ccc}
\hline Sample & Wt. (\%) & $\begin{array}{c}\text { Iron-carbon liquidus } \\
\text { temperature, K }\end{array}$ \\
\hline $\begin{array}{c}\text { Iron-graphite } \\
\text { Iron-graphite-high liquidus } \\
\text { temperature slag }\end{array}$ & 4.3 & 1423 \\
$\begin{array}{c}\text { Iron-graphite-low liquidus } \\
\text { temperature slag }\end{array}$ & 3.6 & 1570 \\
\hline
\end{tabular}



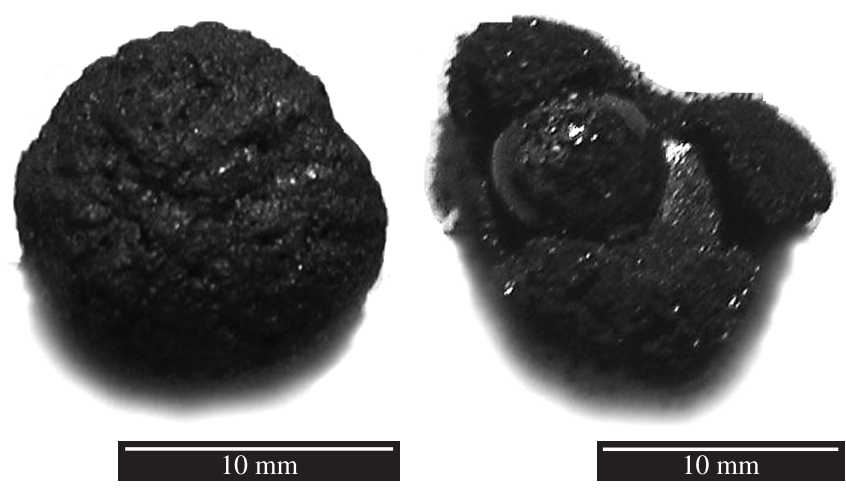

Figure 6. Iron ore-graphite pellets after the experiment; left, pellet with 7\% of Portland ${ }^{\circledR}$ cement (high liquidus temperature slag); right, pellet with $7 \%$ of a mixture of Portland ${ }^{\circledR}$ cement, silica and alumina (low liquidus temperature slag).
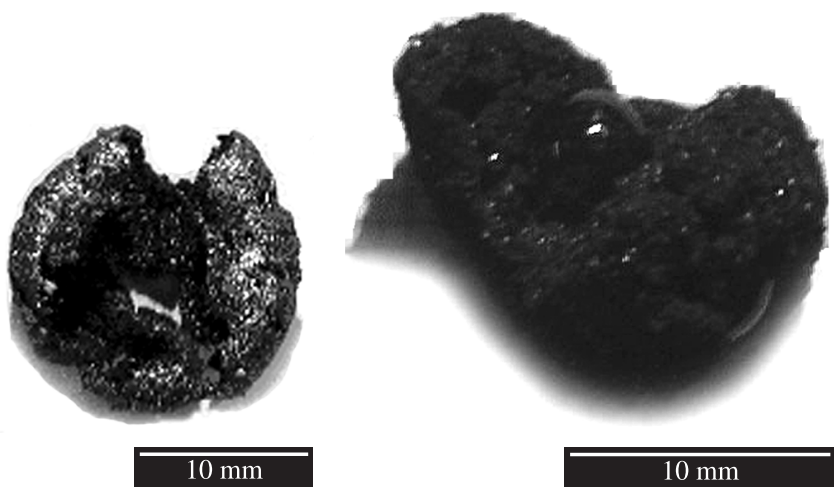

Figure 7. Iron ore-charcoal pellets after the experiments; left, no addition (high liquid temperature slag); right, addition of silica and alumina (low liquidus temperature slag).

\subsection{Experiment with charcoal as reductant}

Experiments were performed applying pellets made from iron ore and devolatized wood charcoal, without any other addition. As in the other experiments, the pellet was first heated to $1573 \mathrm{~K}$ for 600 seconds, in order to promote the iron ore reduction, and then the temperature was raised to $1673 \mathrm{~K}$ and the pellet was maintained at this temperature for 600 seconds in order to produce the iron nugget. The result, shown on Figure 7 (left), presented a sintered iron shell, with slag entrapped, and a hollow center, containing some powdery material. It was not possible to obtain an iron nugget separated from the slag. The devolatized charcoal contains $11.4 \mathrm{wt}$. (\%) ashes, corresponding, before reduction, to around $1.75 \mathrm{wt}$. (\%) of substances that will not be reduced during heating (disregarding the iron oxides in the ashes). The addition of fluxes (silica and alumina) to decrease the liquidus temperature of the slag resulted in the formation of small iron-carbon nuggets separated from powdery material containing slag and small iron particles (Figure 7, right). In this case, it seems that besides the slag the carburization of the metallic iron is less effective with charcoal than with graphite, as pointed out by Iguchi and Endo ${ }^{10}$.

\section{Conclusions}

Based on the results obtained by the present work, it is possible to conclude that to obtain iron-carbon nuggets separated form the slag through carbothermic reduction of iron ores in the form of composite pellets the following conditions should be met: the reduction of the ore by carbon in the composite pellet should be performed at temperatures lower than $1623 \mathrm{~K}$ to avoid loss of carbon at product gases flow; the metallic iron formed by reduction must be carburized, and the carburizing rate is decreased by the presence of ashes from the carbonaceous material; the addition of fluxes to decrease the liquidus temperature of the slag formed by the ashes increases the carburizing rate; the slag formed by the ashes of the carbonaceous material, the gangue of the ore, the binder and the additions should present a liquidus temperature as low as possible.

\section{Acknowledgements}

The authors would like to express their gratitude to the Sao Paulo State Research Foundation (FAPESP) and to the National Research and Development Council of Brazil (CNPq) for financial support to this work.

\section{References}

1. Shimizu M, Nishioka K and Maeda T. Rapid reduction and melting of carbon composite iron ore pellets on high temperature. In Proceedings of Fourth Japan-Brazil symposium on dust processing-energy-environment in metallurgical industries; 2002; São Paulo, Brasil. Sao Paulo: Universidade de São Paulo; 2002. p. 103-114.

2. D’Abreu JCD, Martins KM and Noldin Jr JHY. The iron morphology of self-reducing briquettes, In Proceedings of Fourth Japan-Brazil Symposium on dust processing-energy-environment in metallurgical industries; 2002; São Paulo, Brasil. São Paulo: Universidade de São Paulo; 2002. p. 89-101.

3. Meissner S, Kobayashi I, Tanigak Y and Tacke K. Reduction and melting model of carbon composite ore pellets. Ironmaking and Steelmaking, 2003; 30 (2):170-176.

4. Iguchi Y, Fanming M and Hiura M. Reaction enhancing mechanism in iron ore-carbonaceous material composite pellets heated at elevated temperatures. In Proceedings of Fourth Japan-Brazil symposium on dust processing-energy-environment in metallurgical industries; 2002; São Paulo, Brasil. São Paulo: Universidade de São Paulo; 2002. p. 77-88.

5. Inaba S. Overview of New Direct Reduced Iron Technology. Tetsu-toHagané, 2001; 87(5):221.

6. Matsumura T, Takenaka Y, Shimizu M, Negami T, Kobayashi J and Uragami A. Direct production of molten iron from carbon composite iron ore pellet. La Revue de Métallurgie-CIT, 1998; 95 (3):341-351.

7. Matsui T, Ishiwata N, Hara Y and Takeda K. Fundamental study on the low temperature melting of reduced iron. In Proceedings of Science and Technology of Innovative Ironmaking for aiming at Energy Half Consumption. ISIJ, 2003; 177-180.

8. Ohno K and Hino M. Kinetic analysis of iron carburization during smelting reduction. In Proceedings of Science and technology of innovative ironmaking for aiming at energy half consumption. ISIJ, 2003; 17-20.

9. Eisenhuttenleute VD. Slag Atlas. Germany: Committee for Fundamental Metallurgy; 1981.

10. Iguchi $Y$ and Endo S. Carburized carbon content of reduced iron and direct carburization in carbon composite iron ore pellets heated at elevated temperature. ISIJ; 2004; 44(12):1991-1998. 